\title{
Science workshops in isolated communities in the state of Guanajuato, Mexico
}

\section{Cristina Solano, Antonio Campos, Eleonor Leon}

Cristina Solano, Antonio Campos, Eleonor Leon, "Science workshops in isolated communities in the state of Guanajuato, Mexico," Proc. SPIE 8481, Optics Education and Outreach II, 84810P (15 October 2012); doi: $10.1117 / 12.930037$

SPIE Event: SPIE Optical Engineering + Applications, 2012, San Diego, California, United States 


\title{
Science workshops in isolated communities in the state of Guanajuato, México
}

\author{
Cristina Solano, Antonio Campos and Eleonor León
}

\author{
Outreach Coordination, Centro de Investigaciones en Óptica, A.C. \\ Loma del Bosque 115, Lomas del Campestre, León, Guanajuato, México 37150, \\ divulgación@cio.mx
}

\begin{abstract}
The original initiative or this program was from the Science Council of the State of Guanajuato, and it was extended thanks to the support of the SPIE grant. The outreach coordination supported the idea of visiting elementary schools that belong to remote municipalities or rural schools of the region; we have worked with communities from 30 to 300 miles apart from the city of León. The workshops to be given were chosen, taking into consideration that they needed to be really representative, creative, and demonstrative, useful and at the same time neither expensive nor delicate. The school were reached and in several occasions. At the moment, at least one request of workshops for communities is served every week, where approximately 5000 children had been attended in the last two years.
\end{abstract}

\section{SCIENCE ACADEMY FOR CHILDREN, THE FIST EXPERIENCE}

The program, Science Academy for Children, started with the initiative of the Guanajuato Science Council. The first two years, it was dedicated to children from 10-12 years old, studying in public schools, located near the main research centers. The Science Council formed about 12 different groups with 40 students each one, and organize monthly visits to different research centers during the academic year.

The aim of the Science Academy for Children program is to give the participants some hands on experiences of some work taking place in the research centers in the state. The designed workshops show them that even the basic principles have real applications and that learning new things can be a nice experience. The technical material covered in these workshops it is not related with the material taught during the academic year. Therefore during the presentations every concept has to be clarified and careful explained in a way the students can understand them.

Fore these reasons the experiments shown to the children are basic instruments as kaleidoscopes, periscopes. They use lenses, some small lasers, etc. The important point is to emphasize the theory behind every experiment.

Optics Education and Outreach II, edited by G. Groot Gregory, Proc. of SPIE Vol. 8481 84810P · ( 2012 SPIE · CCC code: 0277-786/12/\$18 · doi: 10.1117/12.930037 
In our case the children visiting our research center have the advantage is that they could visit our small Science Museum and learn more about optics.

Over the years it has been observed that the children have an enthusiastic response to the program, even though an extra effort is needed to have academic activities on Saturdays. An invitation is send to different schools as an unrelated activity to the academic ones.

\section{THE STATE OF GUANAJUATO}

Guanajuato is located in the central part of Mexico representing $1.6 \%$ of the total surface of the country. Our research center is located in the city of Leon, in a zone known as the industrial corridor, and is the biggest city of the state. In this industrial corridor there are located the research centers and the main universities of the Guanajuato state.

As seen in Fig. 2, the Guanajuato state has many mountains isolating many small communities.

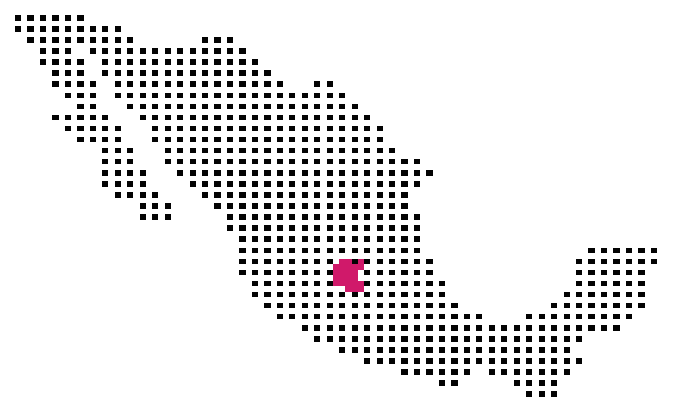

Fig. 1 State of Guanajuato

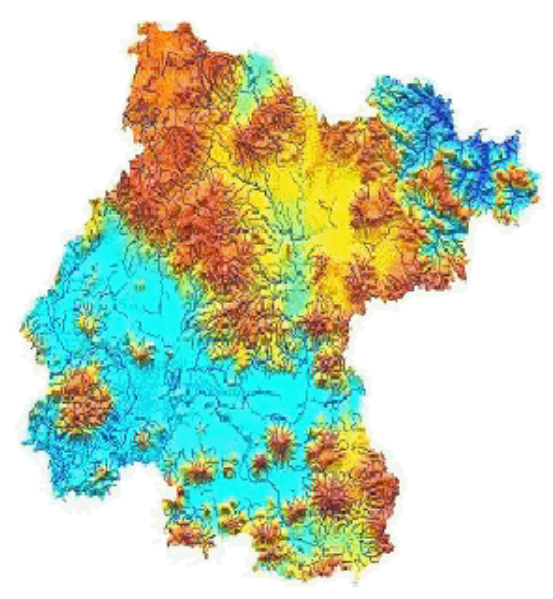

Fig. 2 Guanajuato State

\section{SCIENCE ACADEMY FOR CHILDREN, TO THE INSOLATED COMMUNITIES}


As indicated in the first section the early of the Science Academy for Children program worked with children living near the research centers. This does not mean that they were aware of the activities going on in these places, but the groups could reach these centers in a short time.

The next challenge was to expand the workshops program to the rural areas of the State of Guanajuato, most of them difficult to reach because of the amount of mountains, Fig 2. This fact increase the traveling time and expenses for the children to be incorporated in the original program, therefore some changes in the original scheme were necessary.

In this case, it was organized in the form that one of two members of the research centers visited the different schools in their communities. So, the last two year 13 communities have received monthly visits from different research centers and universities. The academic institutions received a limited amount of money for materials and travel expenses. The visits are covered mainly by graduate students.

It is the responsibility of each institution that the graduated students received proper training about the workshops and some ideas about their work with children.

This program has been developed very closely with the Education authorities as they are responsible to find the schools and organize the groups. It is maintained for children from 10 to 12 years old. It was observed that the participants are very enthusiastic and really want to learn different things. None of them is forced to attend the workshops as they take place in Saturdays.

The workshops given were chosen, taking into consideration that they needed to be really representative of the research field, optics in our case, creative, demonstrative, useful, and at the same time neither expensive nor delicate. The children received 3 hrs workshops from different scientific themes. We have visited at least 12 communities each academic year.

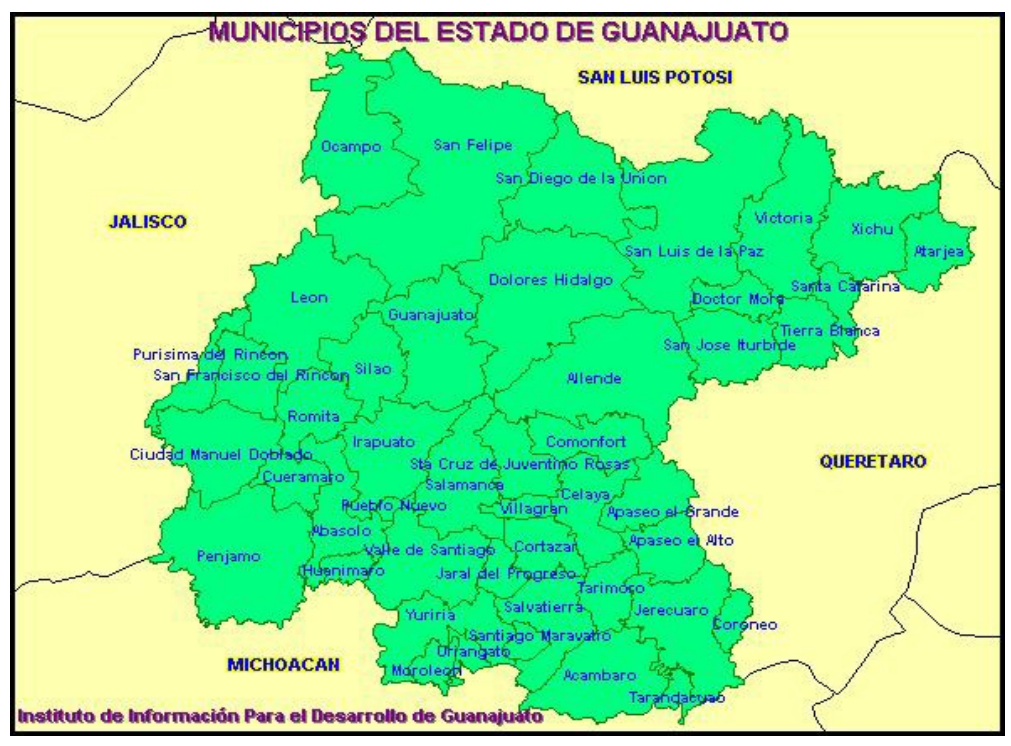

Fig. 3 Political division of the Guanajuato State 


\section{Communities visited:}

Allende, Apaseo, Acambaro, Dolores Hidalgo, Jaral del Progreso, Ocampo, San Felipe, San Luis de la Paz, San Jose Iturbide, Uriangato, Victoria y Yuriria. As an example, the distance from Leon to Victoria is more tan 300 miles, 2.5 hours driving.

The first year, it was decided that our theme should be solar energy and in particular solar kitchens. Depending of the graduated student interest, some of them made more emphasis on solar clocks nevertheless the subject is interesting enough for the children receiving an important message about an alternative way to use the energy that can improve their economy.

During the second year the children work with simple optical instruments, as kaleidoscopes, periscopes, uv light and light graffiti.

At the moment, at least one request of workshops for communities is served every week, where approximately 5000 children had been attended last year.

The Science Council gave us a limited amount of money to cover the material and a small grant were provided and with the aid of SPIE grant we were able to complete the travel expenses and the materials needed. SPIE increased the impact of the amount of students that benefit with this activity.

\section{CONCLUSIONS}

Our experience shows that we can teach basic science with an adequate program to students regardless their economic limitations. We really hope these activities give them a different attitude toward their future and motivate them to continue their studies.

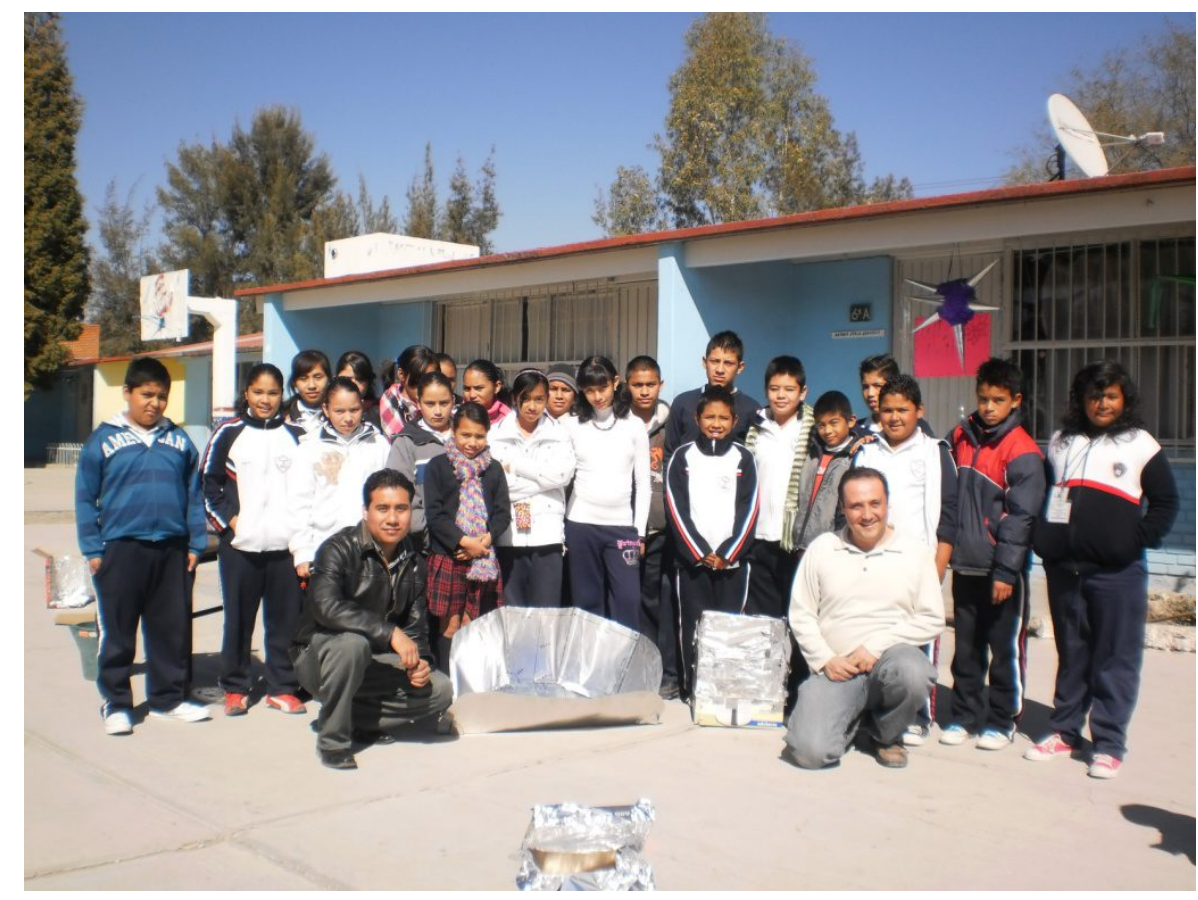

